\title{
Aflatoxin-specific monoclonal antibody selection for immunoaffinity column development
}

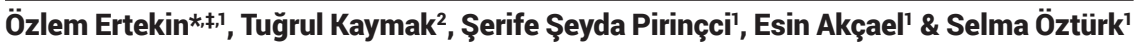

\begin{abstract}
Antibodies are the basic components of immunoanalytical systems used for detection of a wide range of analytes. Although there are some ground rules for antibody selection, analyte- and assay-specific criteria are the ones that determine the ultimate success of the immunoassays. In this study, we introduced an effective antibody selection procedure for the development of immunoaffinity columns for aflatoxins. The designed scheme puts emphasis on solvent- and matrix-related characterization steps and was used to comparatively evaluate eight monoclonal antibodies. The selected antibody was tolerant to $40 \%$ methanol, $20 \%$ acetonitrile, $30 \%$ acetone and $40 \%$ ethanol and did not interact with corn, red pepper or hazelnut extracts. Immunoaffinity columns developed with the selected antibody were validated by 15 independent aflatoxin analysis laboratories.
\end{abstract}

\section{METHOD SUMMARY}

This article describes a systematic methodology to select the best monoclonal antibody to be used in aflatoxin immunoaffinity columns. The scheme consists of four critical steps. Highly specific antibodies were selected that interact with aflatoxin derivatives but not with other mycotoxins. High tolerance to the solvents used in aflatoxin extraction protocols was assured. The antibodies that interact with food extracts were eliminated. Finally, the antibodies were functionally tested for effective integration to immunoaffinity columns where resin binding efficacy and column performances were evaluated. The developed columns were validated by 15 independent laboratories to show the efficacy of the selection scheme.

\section{KEYWORDS:}

antibody selection $\cdot$ immunoaffinity column $\cdot$ matrix interference $\cdot$ mycotoxin analysis $\cdot$ solvent tolerance

'TÜBITAK, The Scientific \& Technological Research Council of Turkey, Marmara Research Center, Genetic Engineering \& Biotechnology Institute, 41470 Gebze, Kocaeli, Turkey; ${ }^{2}$ Republic of Turkey Ministry of Food Agriculture \& Livestock, General Directorate of Food \& Control, Turkey; *Author for correspondence: ozlem.ertekin@gmail.com; ${ }^{\ddagger}$ Current affiliation: Institute of Biomaterials, University of Erlangen-Nuremberg, 91058 Erlangen, Germany

BioTechniques 66: 261-268 (June 2019) 10.2144/btn-2018-0143
Immunoanalytical systems utilizing the specificity and sensitivity of antibodies are widely used in food contaminant analysis [1-6]. They can be used as alternatives to the instrumental systems such as ELISA; as complementary systems for initial screening of the samples like strip tests; or integrated into protocols of instrumental analysis such as sample cleanup with immunoaffinity columns (IACs). Emerging technologies such as biosensors also utilize the selectivity of the antibodies [2,5-9]. Monoclonal antibodies (mAbs) are preferred in commercial immunoanalytical systems since they provide high batchto-batch reproducibility and choosing the best $\mathrm{mAb}$ to work with is the most critical factor for the success of the developed system [10-13]. mAb selection process should be considered in a broad perspective, starting from laboratory performance of the antibody to commercial production costs of the system. Specificity and affinity are the initial criteria used for the selection of the desired antibody $[10,14,15]$. Beyond that, a new set of criteria should be established for every analyte and every immunoanalytical system to be considered [12,16].

Aflatoxins (AFs) are the toxic secondary metabolites of the fungi from Aspergillus spp. [17]. In order to prevent AF-associated health risks, maximum allowable AF limits for food and feedstuff are regulated $[18,19]$. The AF analysis systems accepted by the regulations include instrumental analysis with HPLC or LC-MS/MS; and immunological test methods including ELISA [20,21].

mAbs against AFs are conventionally required to measure four naturally occurring AF derivatives and one water soluble metabolite in food and feedstuff $[22,23]$. Thus, the specificity of the antibody should be assessed so that it has affinity towards AFB1, -B2, -G1, -G2 and -M1, yet does not display cross-reactivity to other mycotoxins. Additionally, solvent tolerance and minimal matrix interference with food extracts should also be considered since AF analysis is conducted with a liquid extract of the sample to be analyzed as exemplified for nanobodies [24]. Preparation of the liquid extracts of solid samples is achieved using organic solvents. During the extraction process, several metabolites of the sample are co-extracted with the AF. For an antibody to be effectively utilized in AF analysis it needs to be tolerant to solvents used in the extraction process and should not crossreact with the food components present in the extract.

Assay-specific requirements can then be considered for selection to ensure the effective integration of the antibody to the desired immunoassay. Each immunoanalytical system has its own requirements. For instance, for ELISA test development, depending on the immunoassay design, the antibody should be functional after enzyme conjugation, or be able to functionally bind to the ELISA test surface. For IAC development, binding efficiency to the chosen resin and functionality after binding is important [10]. Moreover, the antibody should stably bind the antigen under flow.

The efficacy of the selected antibody in the analysis is demonstrated at lab scale as explained. When the commercial production of the systems is of question, the production costs and shelf life should also be considered. Hence, antibody production performance and purification requirements are other factors to be evaluated. Selection of the 


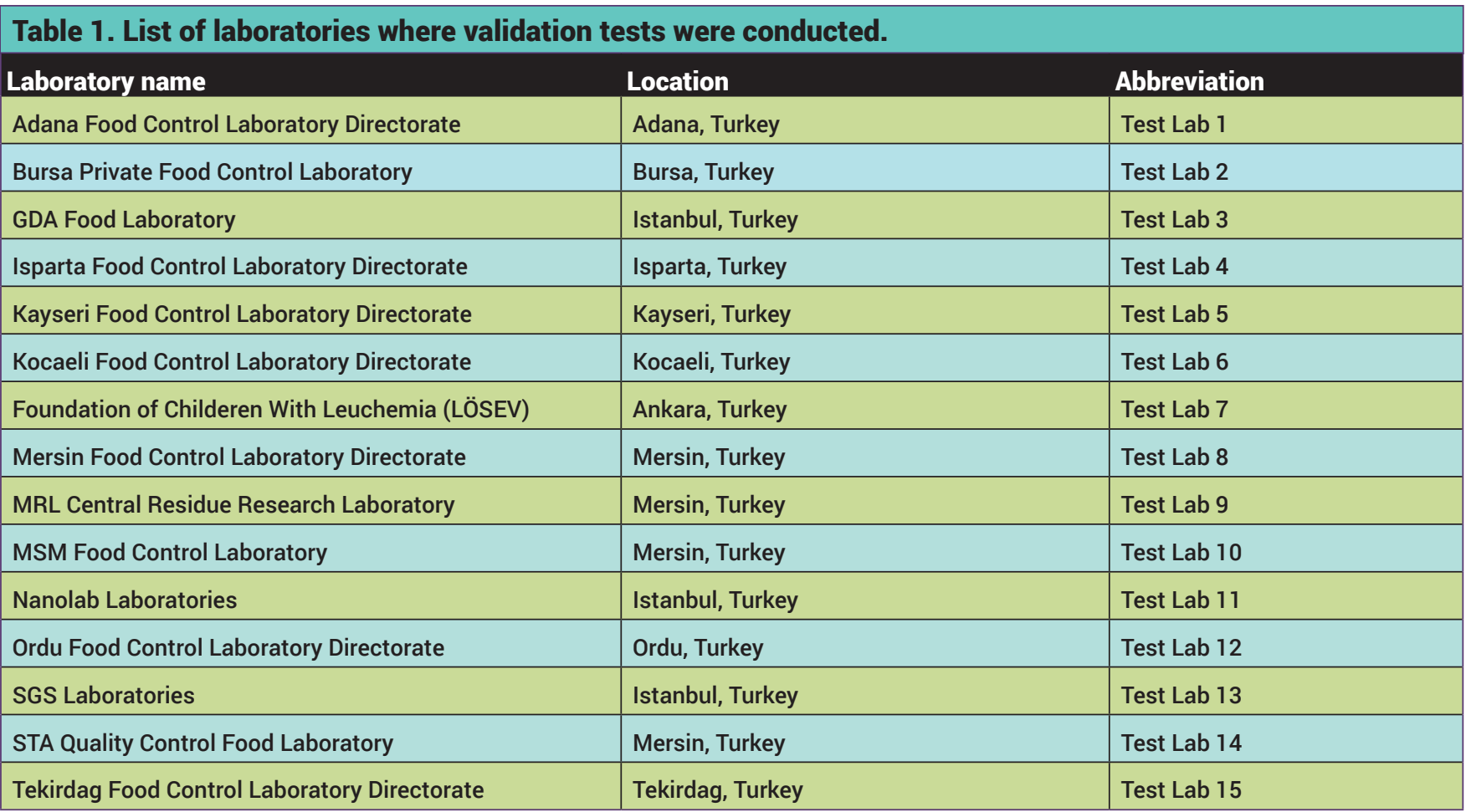

best antibody is inevitably the selection of the best cell line and the properties of the cell line directly influences the production costs. A suitable monoclonal cell line should be stable and productive in terms of both cell growth and antibody production to be able to sustain long-term production of the desired antibody. Media requirements of the cell line should be minimized without diminishing antibody production $[10,25]$. Most of the antibodies need to be purified prior to use. The purification step both increases the production costs and inversely affects the activity of the antibody $[26,27]$, so the availability of a feasible purification scheme is another important criteria. The antibody should either show sufficient performance when it is not fully purified, or a cost-effective purification scheme that does not affect antibody activity should be established.

In this study, we propose a systematic antibody selection approach for AF IAC development using in-house-developed AF antibodies. The success of the approach was demonstrated by pilot scale production and validation of the IACs prepared with the selected antibody.

\section{MATERIALS \& METHODS}

Hybridoma clones \& antibodies

In this work, in-house-developed anti-AF mAbs were used $[28,29]$. A protein cross- reactivity test was performed by indirect ELISA with 100 ng BSA, human Apo transferrin or ovalbumin-coated ELISA plates using $100 \mu \mathrm{l}$ cell culture supernatants.

Hybridoma clones were cultured in DMEM supplemented with $10 \%$ fetal bovine serum and $0.1 \%$ gentamycin at $37^{\circ} \mathrm{C}$ in the presence of $5 \% \mathrm{CO}_{2}$ with $90 \%$ humidity. Cell culture supernatants containing the antibodies were concentrated and partially purified with $40 \%$ ammonium sulphate (AS) precipitation [30].

\section{Determination of antibody specificity} with competitive indirect ELISA

Interaction of antibodies with soluble mycotoxins were tested by competitive indirect ELISA (CI-ELISA) with AFB1, -B2, -G1,-G2,-M1, OA and ZEA. ELISA plates were coated with $500 \mathrm{ng}$ AFB1-BSA. $50 \mu \mathrm{l}$ cell culture supernatant was mixed with $50 \mu \mathrm{l}$ of $0.02 \mathrm{mg} / \mathrm{ml}$ solution of each specified mycotoxin and incubated for $30 \mathrm{~min}$ at $37^{\circ} \mathrm{C}$. Cell culture supernatants were mixed with PBS as negative control. Visualization was achieved using alkaline phosphatase (AP)-conjugated goat anti-mouse polyvalent antibody with 4-nitrophenyl phosphate as AP substrate. Absorbance at $405 \mathrm{~nm}$ was measured with a microplate reader (Biotek Synergy HT).
Determination of solvent tolerance

$0-70 \%$ aqueous solutions of methanol, acetonitrile, acetone and ethanol were prepared. AS precipitates of the antibodies were 500 -fold diluted with these solutions and incubated at room temperature for $5 \mathrm{~min}$. Antibody binding was tested by indirect ELISA with three independent replicas.

\section{Extract cross-reactivity \& aflatoxin} interaction in food matrices

Reactivity of antibodies with corn, red pepper and hazelnut extracts prepared according to directives [31] were determined by CI-ELISA. $1 \mathrm{ml}$ of 1000-fold PBS diluted AS precipitated antibody was preincubated with $1 \%$ of food extracts or $70 \%$ methanolwater solution with or without AFB1 contamination for $30 \mathrm{~min}$ at $37^{\circ} \mathrm{C}$.

\section{Affinity determination}

$50 \%$ inhibition $\left(\mathrm{IC}_{50}\right)$ values for the developed antibodies were calculated by CI-ELISA where $0.2 \mathrm{mg} / \mathrm{ml}$ antibody was used for competition with AFB1 at concentrations ranging from 0 to $7 \mathrm{ng} / \mathrm{ml}$. The competition reaction proceeded for $30 \mathrm{~min}$ at $37^{\circ} \mathrm{C}$.

\section{Immunoaffinity column preparation}

CNBr-activated sepharose 4B was used according to the manufacturer's instructions. 
AS precipitates of the antibodies were used for IAC development containing 60,30 or $10 \mu \mathrm{g}$ antibody per column. Sepharose binding efficiency was evaluated by measuring absorbance at $280 \mathrm{~nm}$ wavelength prior to and after immobilization. $400 \mu$ lantibody-bound resin per column was used.

\section{Overflow test}

AF binding capacity of the columns was evaluated with overflow test, where $500 \mathrm{ng}$ AFB1, -B2, - G1 or -G2 was loaded to IACs in $23.3 \%$ methanol-water solution with three replicas. Columns were washed with $10 \mathrm{ml}$ water and AFs were eluted with $1 \mathrm{ml}$ methanol. Eluates were diluted with equal volume of water prior to HPLC analysis using 250/4,6 Nucleosil ${ }^{\circledR}$ 100-5 C18 column (Macherey-Nagel 720014.46) with KOBRA cell derivatization. $55 \% \mathrm{KBr}-\mathrm{HNO}_{2}$ buffer $+27 \%$ methanol $+18 \%$ acetonitrile was used as mobile phase at $1 \mathrm{ml} / \mathrm{min}$ flow rate. Fluorescence detection at $360 \mathrm{~nm}$ excitation and $430 \mathrm{~nm}$ emission wavelengths was used.

\section{Shelf life test}

IACs prepared in $0.02 \% \mathrm{NaNO}_{3}$ containing PBS were evaluated with overflow test after 6,9 and 12 months of cold storage.

\section{Validation of IACs}

Validation was performed by 15 independent certified analytical laboratories in Turkey with 5 ppb AF limit binding test. The list and abbreviations of the laboratories are presented in Table 1.

Hazelnut and wheat flour samples were spiked with 5 ppb of AFB1, -B2, -G1 and -G2. Extracts prepared according to AOAC 999.07 and AOAC 991.31, respectively, were diluted to yield $14-16 \%$ final methanol concentration. Columns were tested for recovery of $5 \mathrm{ng} \mathrm{AF} .20 \mathrm{ml}$ contaminated extract was loaded to the columns at $3 \mathrm{ml} / \mathrm{min}$ flow rate and the columns were washed with $20 \mathrm{ml}$ distilled water at the same flow rate. The bound AFs were eluted with $1 \mathrm{ml}$ methanol and diluted with equal volume of water prior to HPLC analysis.

\section{RESULTS \& DISCUSSION}

Antibody specificity assessment

AFs are small molecular-weight compounds that cannot generate immune response in the experimental animals used in the

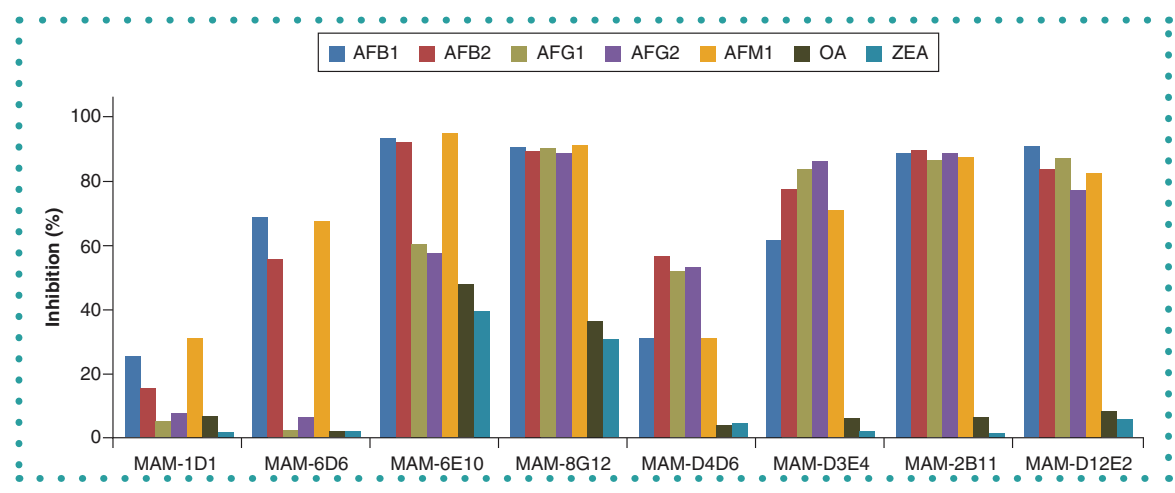

Figure 1. Competitive indirect ELISA showing the interaction of antibodies with $1 \mu \mathrm{g}$ free AFB1, -B2, $-G 1,-G 2,-M 1, O A$ and ZEA. Inhibition rates were calculated with respect to no mycotoxin bearing positive control. Results are the mean of two independent replicas.

AF: Aflatoxin.

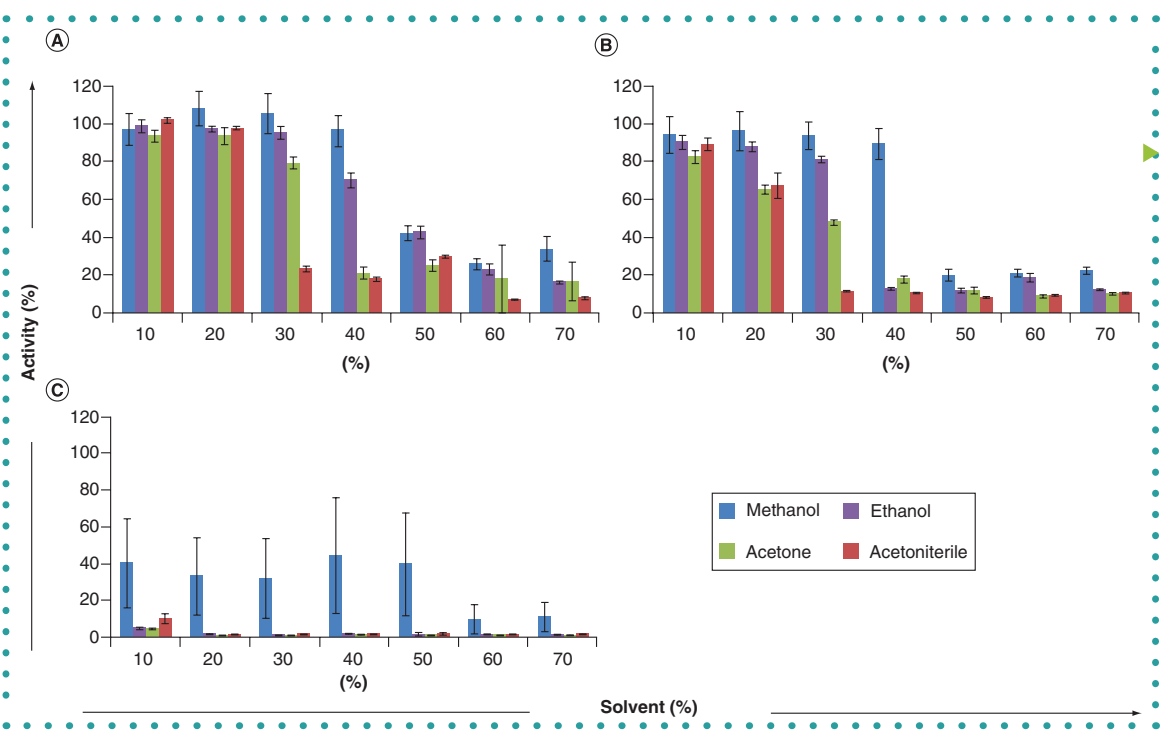

Figure 2. Tolerance of antibodies to different concentrations of methanol, ethanol and acetonitrile demonstrated with ELISA. (A) D12E2, (B) 2B11, (C) D3E4. The results are presented as the mean of three replicates. Error bars represent standard deviations.

antibody development process. So, protein conjugates of AFs were used for immunizations and subsequent ELISA tests. Since the antibody-producing positive clones were also selected with protein conjugates, specifically AFB1-BSA conjugate, the antibodies may be responsive to $A F B 1, B S A$ or the chemical bond between these molecules. Thus, the developed antibodies were selected so that produced antibodies do not recognize proteins but effectively bind to free toxins.

The antibody selection process started with 121 antibody-producing hybrid cells obtained from three hybridoma fusions. We tested the supernatants of the antibodyproducing hybridoma clones for their crossreactivity with the proteins used in AF conjugation. 1D1, 6D6, 6E10, 8G12, D4D6,
D3E4, 2B11 and D12E2 tested negative for protein binding.

Selected clones were further evaluated for AF specificity by mycotoxin inhibition assay with $\mathrm{CI}$-ELISA. The preferred antibody should recognize AFB1, -B2, -G1, -G2 and -M1 to be used for the detection of all AF isotypes simultaneously and should not bind to other mycotoxins. Therefore, the clones were tested for binding to OA and ZEA as well as $A F$ isotypes in order to assess specificity. The results of mycotoxin inhibition assay are presented as inhibition rate (\%) with respect to control antibody, which was not subjected to competition (Figure 1). 1D1 and D4D6 failed to interact with soluble toxins. 6E10 and $8 \mathrm{G} 12$ cross-reacted with $\mathrm{OA}$ and ZEA. $6 \mathrm{D} 6$ interacted with AFB1, -B2 and -M1, but 


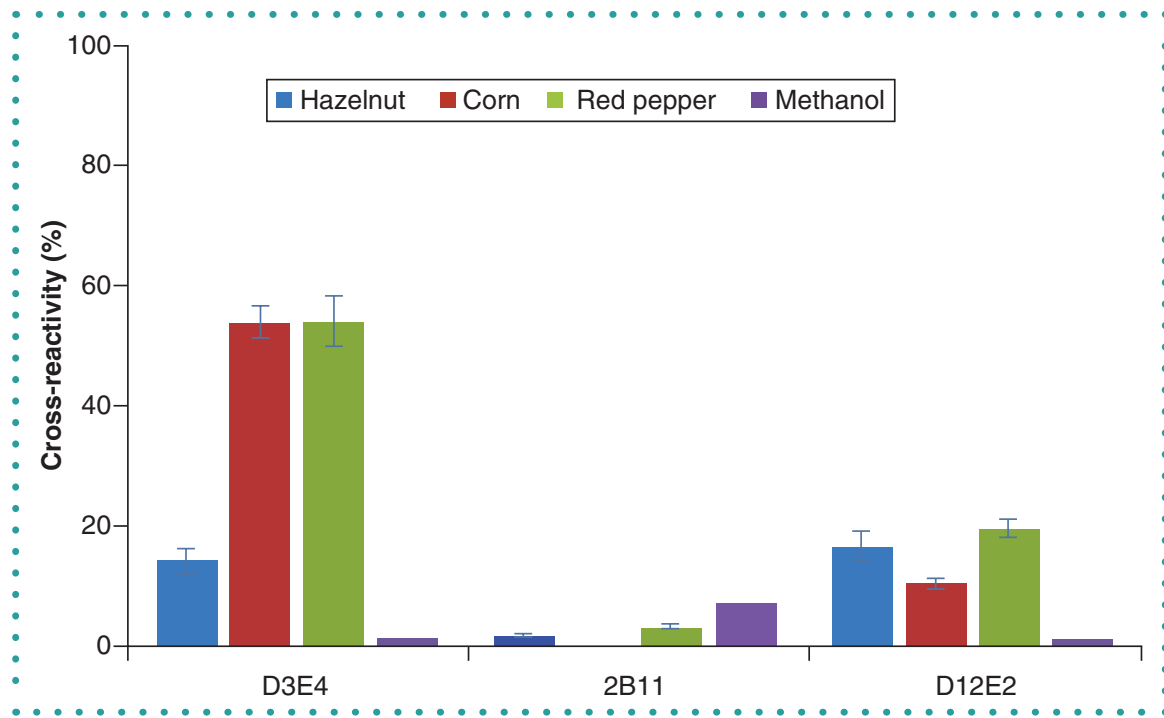

Figure 3. Competitive indirect ELISA showing the cross-reactivity of D12E2, 2B11 and D3E4 with aflatoxin-free corn, pepper and hazelnut extracts with respect to noncompetitive ELISA results with the same antibodies in phosphate-buffered saline.

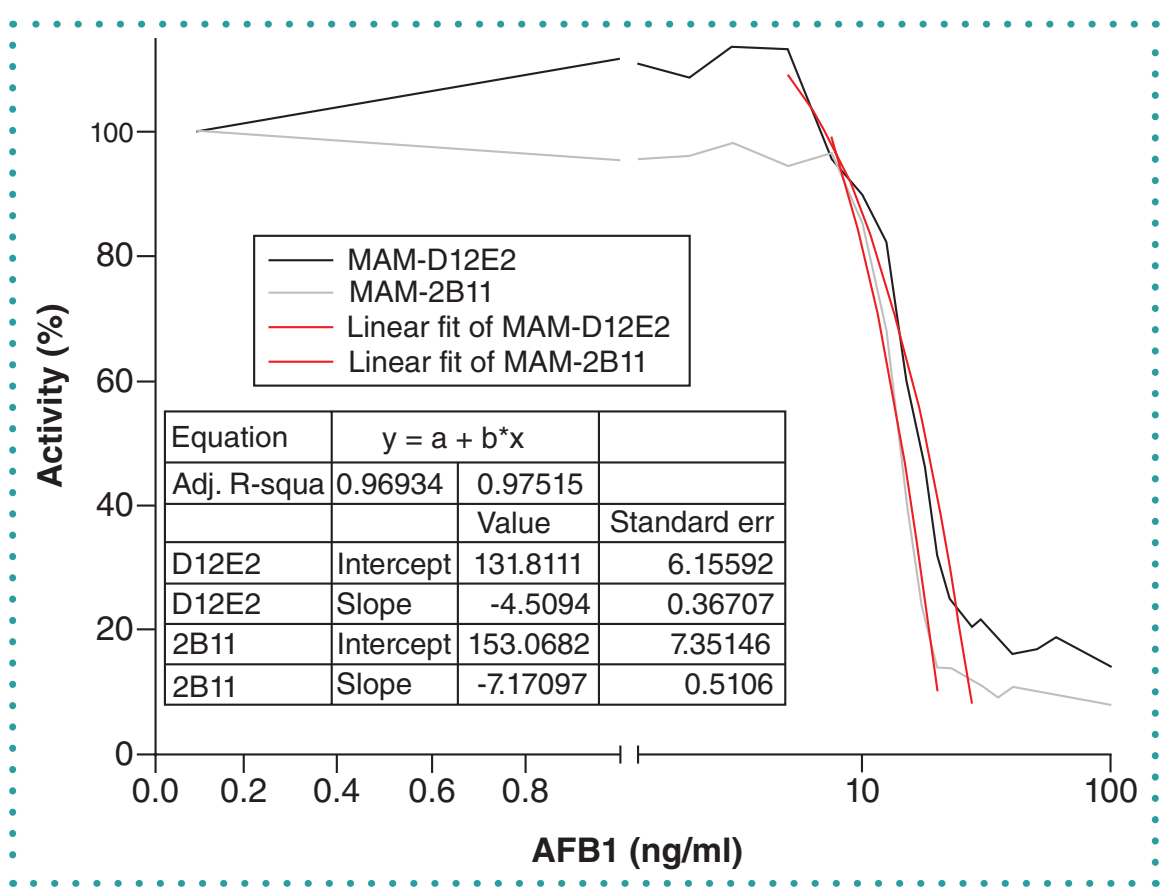

Figure 4. Binding inhibition curves of D12E2 and 2B11s.

did not bind to AFG1 and -G2 and hence did not qualify with the requirement to bind to all AF isotypes. However, this antibody may be used for specific determination of these isotypes when required. Antibodies D3E4, 2B11 and D12E2 recognized all AF isotypes and showed no cross-reactivity with OA and ZEA. Therefore, the selection proceeded with these antibodies.

\section{Solvent tolerance \& matrix interference} The selected antibody will be used in IAC of the antibodies in these solvents are presented in Figure 2. D12E2 was tolerant to $40 \%$ methanol, $20 \%$ acetonitrile, $30 \%$ acetone and $40 \%$ ethanol (Figure $2 \mathrm{~A}$ ). In 20 and $30 \%$ methanol concentrations, the signal was higher than control in PBS. This is probably due to the slight clumping of antibody molecules at these concentrations. The binding sites were still fully functional, but once a single antibody molecule was bound to the ELISA plate the clumped antibodies also contributed to the signal, which resulted in an elevated signal. However, this clumping does not pose a problem in IAC systems as far as binding sites are active because, in IAC's, antibodies will be immobilized to a solid support before encountering the solvent. 2B11 was tolerant to $40 \%$ methanol, $20 \%$ acetonitrile, $20 \%$ acetone and $30 \%$ ethanol (Figure $2 \mathrm{~B}$ ). D3E4 was not tolerant to organic solvents (Figure 2C). Solvent tolerance of D12E2 was higher than 2B11; however, both antibodies can be utilized in detection systems.

In order to assess the matrix interference effect, D12E2, 2B11 and D3E4 were evaluated with competitive indirect ELISA with $1 \%$ corn, red pepper and hazelnut extracts (Figure 3 ). D12E2 showed slight reaction with hazelnut and red pepper extracts. 2B11 did not bind to any of the extracts tested for cross-reactivity. D3E4 showed strong cross-reactivity with corn and red pepper extracts.

Low solvent tolerance and high extract cross-reactivity of D3E4 made the antibody unsuitable to be used in AF analysis, so the selection process was advanced with D12E2 and $2 \mathrm{~B} 11$.

\section{Affinity determination of antibodies}

D12E2 and 2B11 underwent competitive interaction with differing AFB1 concentrations to determine the affinities. The resulting binding inhibition curves are presented in Figure 4. D12E2 and 2B11, which were selected as potential candidates for IAC development, had 0.85 and $2.77 \mathrm{ng} / \mathrm{ml}$ $I_{50}$ values for AFB1, respectively.

The 2B11 mAb showed both lower tolerance to solvents and lower affinity when compared with D12E2. However, D12E2 showed slightly higher interaction with food extract components when compared with 2B11. They are both feasible alternatives for IAC development. In order to determine the best candidate for IAC development, 
the interaction of the mAbs with AF in food extracts should be evaluated.

\section{Evaluation of AF-antibody interaction in} food extracts

In the next step of selection, we evaluated the reactivity of the antibodies with low concentrations of AFB1 in food extracts. D12E2 and 2B11 were tested for their reactivity with 0.1 to 20 ppb AFB1 in corn, red pepper and hazelnut extracts or $70 \%$ methanol by $\mathrm{Cl}$-ELISA. The resulting binding inhibition curves are presented in Figure 5. The results showed that D12E2 effectively bind to the AFB1 in different matrices at less than $2 \mathrm{ppb}$ concentration (Figure $5 \mathrm{~A}$ ). 2B11 also interacted with free AFB1 in methanol and food extracts; however, binding inhibition curves showed less effective interaction of 2B11 with free AFB1 (Figure 5B). Consequently, D12E2 was selected to be utilized in IAC development.

\section{IAC development}

In the next step, the immobilization efficiency of the selected antibody to the resin and the functional binding to the antigen after immobilization were evaluated. D12E2 was immobilized to CNBr-activated sepharose at three different concentrations. Sepharose-binding efficiency of the antibody increased with increasing starting concentration of AS-precipitated D12E2 in binding buffer. Columns prepared with three different starting protein concentrations retained 10,30 and $60 \mu \mathrm{g}$ antibody (Table 2).

The overflow test results showed that the IACs prepared by partially purified D12E2 antibody were able to bind free AFs when immobilized to the columns. AF binding increased with increasing amount of immobilized antibody as expected (Figure 6). $60 \mu \mathrm{g}$ D12E2 immobilized columns were able to retain more than $100 \mathrm{ng}$ AFB1, which is the requirement for the valid standards [32]. Therefore, we chose $60 \mu \mathrm{g}$ antibody per column for pilot scale IAC production.

Columns prepared similarly with 2B11 and D12E2 were used for the comparison of column performances of the mAbs. The results indicated that IACs prepared with 2B11 had significantly lower performance for AFB1, -B2 and -G2 binding when compared to D12E2 (Figure 7), which indicated the reliability of the proposed selection protocol.

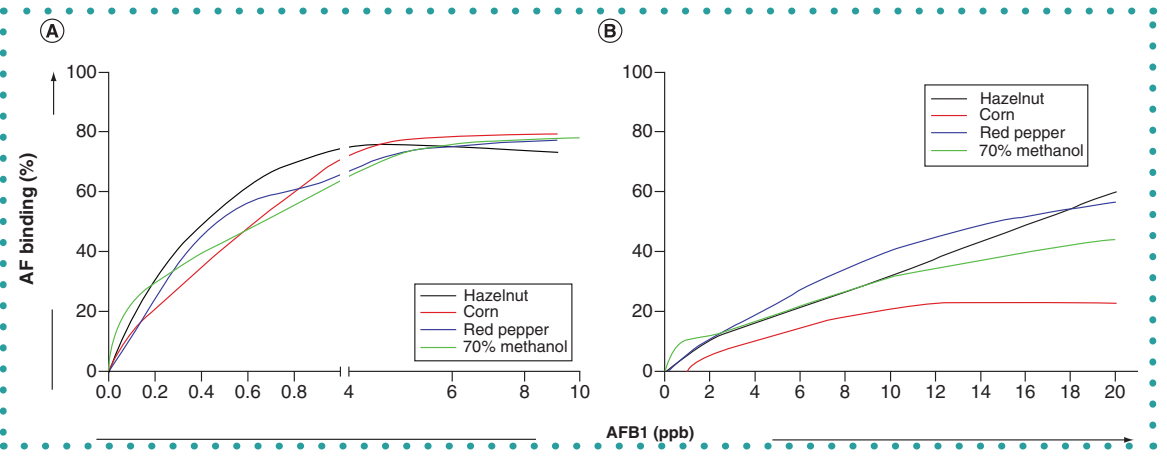

Figure 5. The results of the competitive indirect ELISA showing the interaction of antibodies with AFB1 in $70 \%$ methanol or food extracts spiked with different concentrations of AFB1. Antibody binding as presented with respect to noncompetitive binding of antibodies in phosphate-buffered saline. (A) D12E2 and (B) $2 B 11$.

AF: Aflatoxin.

\section{Shelf-life tests}

We produced 1000 IACs with D12E2 to be used in shelf life tests and validation studies. Columns were evaluated according to their total AFB1 binding capacity for shelf-life tests. The results showed no reduction in column performance after 6,9 and 12 months of storage at $+4^{\circ} \mathrm{C}$ after preparation (Figure 8).

\section{Validation of IACs}

Developed columns were validated in hazelnut and wheat flour samples with limit-binding tests. Recovery rates of $5 \mathrm{ng}$ AFB1, -B2, -G1 and -G2 loaded to the IACs in hazelnut extract are presented in Figure $9 A$ and for wheat flour extract are presented in Figure 9B. Validation was conducted by 15 independent labora- -

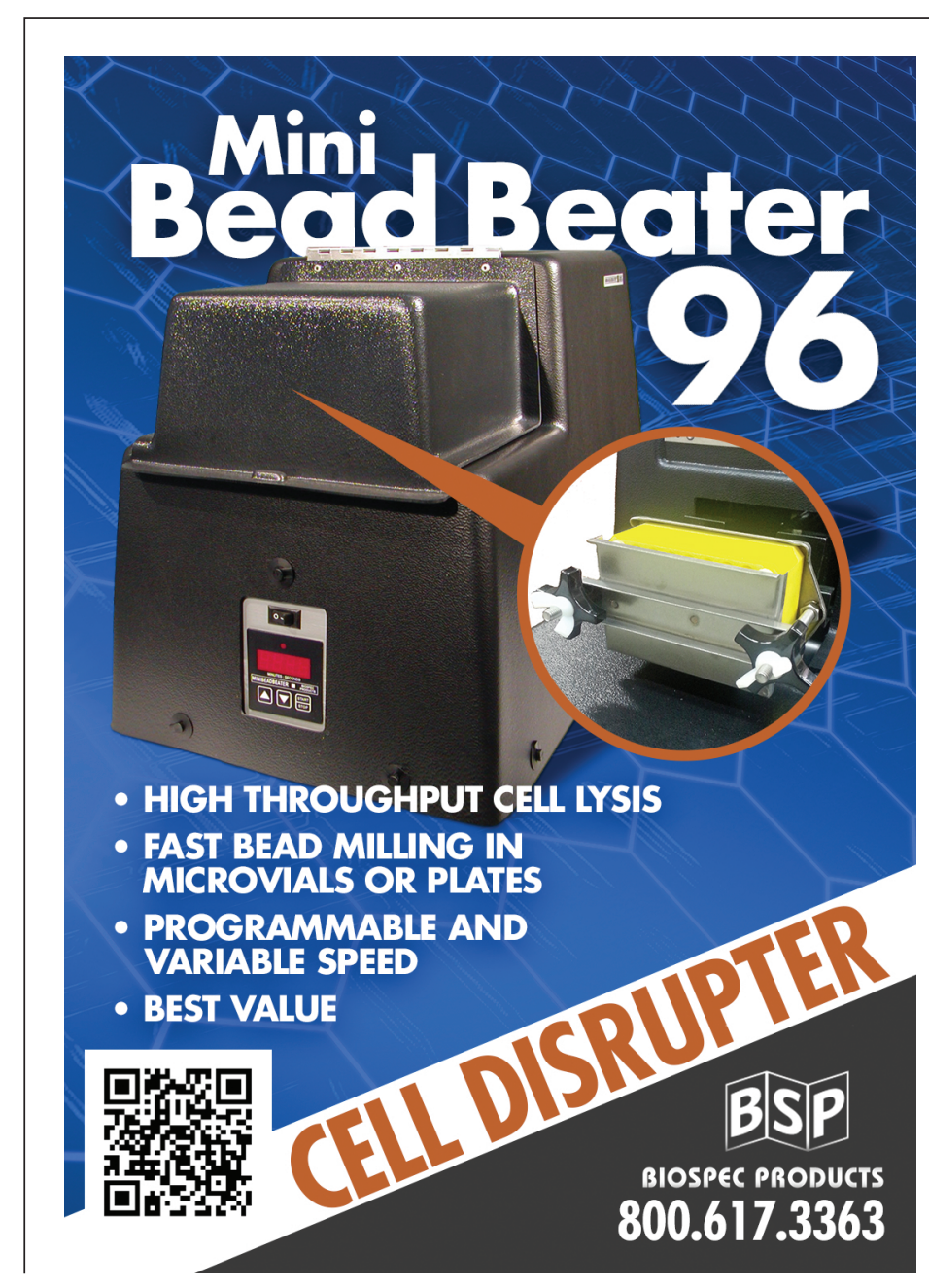




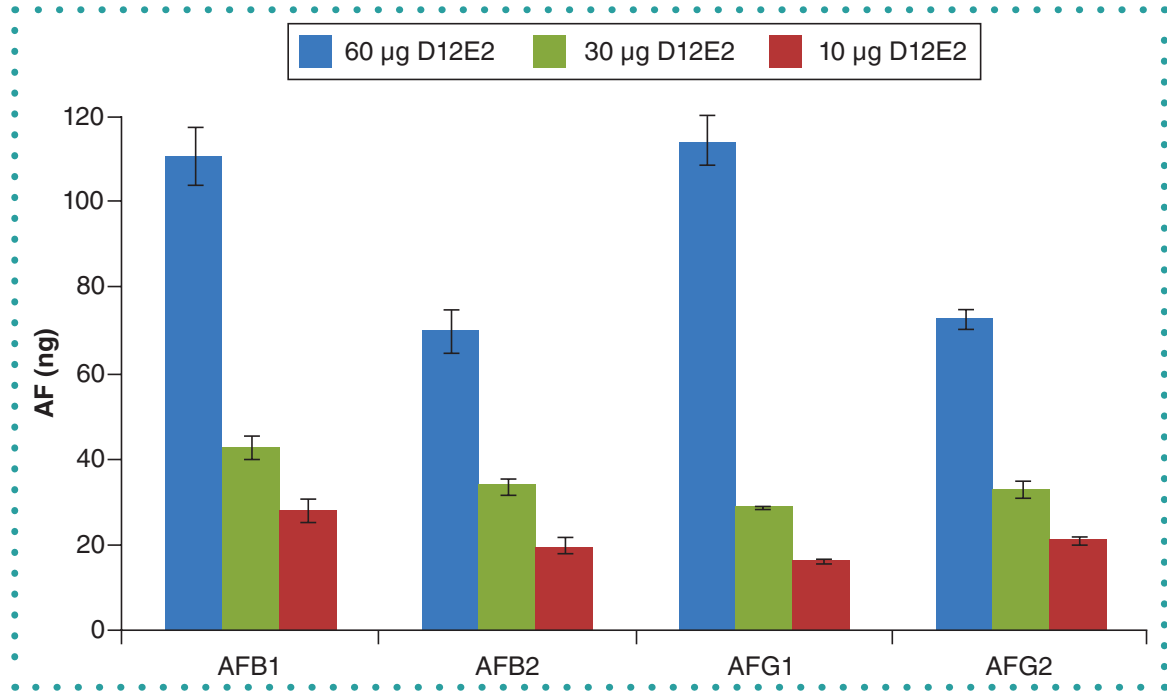

Figure 6 . AFs binding to differentially prepared columns. Total binding capacity of the columns prepared by immobilization of 10,30 and $60 \mu \mathrm{g}$ D12E2 was evaluated for their total binding capacity to $A F B 1,-B 2,-G 1$ and $-G 2$. Error bars represent standard deviations of three independent replicas. AF: Aflatoxin.

Table 2. Sepharose-binding efficiency of D12E2 and antibody contents of prepared columns.

\begin{tabular}{|c|c|c|}
\hline $\begin{array}{l}\text { Total protein concentration in IAC } \\
\text { binding buffer ( } \mathrm{mg} / \mathrm{ml})\end{array}$ & $\begin{array}{l}\text { IAC protein binding } \\
\text { efficiency (\%) }\end{array}$ & Antibody/column $(\mu \mathrm{g})$ \\
\hline 1.5 & 84.7 & 60 \\
\hline 0.75 & 82.8 & 30 \\
\hline 0.3 & 68.2 & 10 \\
\hline
\end{tabular}

$\checkmark$ tories each with six replicas. Results were initially evaluated by Grubbs' test and outliers were ignored. The results showed 93.5 and $98.5 \%$ recovery of $\mathrm{AFB1} ; 88$ and $90.7 \%$ recovery of AFB2; 97.2 and $102.3 \%$ recovery of AFG1; and 88.4 and $79.9 \%$ recovery of AFG 2 in wheat flour and hazelnut extracts, respectively. The columns showed high in-laboratory and interlaboratory repeatability. Inter-laboratory percent repeatability relative standard deviation of the columns were 5.0, 6.0, 5.7 and $5.8 \%$ in wheat flour extract and $4.0,3.6,4.2$ and $4.9 \%$ in hazelnut extract for $A F B 1,-B 2,-G 1$ and $-\mathrm{G} 2$, respectively. These values are confidently within limits of official AF analysis guidelines of the Association of Official Analytical Chemists (AOAC) [31].

\section{CONCLUSIONS}

In this work, we highlighted the important criteria for mAb selection for AF IAC development. The initial criteria for selection of the antibody-producing hybridoma clones is specificity, where the produced antibodies should be able to interact with free AF isotypes but not with proteins used in immunization or other mycotoxins. Antibodies were evaluated for solvent tolerance and extract cross-reactivity where high solvent tolerance may also facilitate further studies leading to reusable IACs by the optimization of elution conditions [33]. Suitable candidates were tested for their toxin-binding performance in food extracts and their affinity towards AFs. The best candidate was integrated into the assay to evaluate its performance.

In the case where more than one antibody succeeds against these selection criteria, the next level of selection should deal with production costs, where culture requirements of the hybridoma clone and antibody production yield are considered [34]. Moreover, a feasible antibody purification scheme should be established to prevent activity loss and preserve yield.

D12E2 was selected from among 121 candidate antibodies using the proposed selection scheme and used for pilot scale IAC production. The success of the selection scheme was demonstrated by the validation of the IACs to be used in real food matrices by 15 independent laboratories. The proposed selection scheme for AF-specific antibody selection for IAC development is presented in Figure 10.

\section{FUTURE PERSPECTIVE}

This selection process, which was demonstrated with IAC development using AF as the model target, can be used for antibody development for other mycotoxins, and analytes that are extracted with organic solvents with slight modifications. For IAC development, we evaluated the resinbinding efficiency of the antibodies and AF-binding performance of the immobilized antibodies. The selection procedure is also applicable to other immunoanalytical platforms with minor modifications. Hence, this work can be used as a guideline for antibody selection for various mycotoxin analysis methods.

\section{AUTHOR CONTRIBUTIONS}

Özlem Ertekin conducted the experiments and wrote the paper. Șerife Șeyda Pirinçci and Esin Akçael worked in antibody development studies. Tuğrul Kaymak organized the validation work and prepared the samples to be distributed to independent laboratories. Selma Öztürk was the principal investigator, supervised the experimental work and critically reviewed the manuscript.

\section{ETHICAL DISCLOSURE}

In this research, we used in-house-developed antibody-producing clones produced by a hybridoma technique. The development of the clones, which is not disclosed as a part of this manuscript, involved the use of experimental animals. Animal experiments were performed in compliance with the appropriate laws and institutional guidelines with the approval of TÜBITAK Marmara Research Center, Genetic Engineering and Biotechnology Institute ethical committee.

\section{ACKNOWLEDGMENTS}

We are grateful to Adana Food Control Laboratory Directorate, Bursa Private Food Control Laboratory, GDA Food and Feed Analysis and Control Laboratory, Isparta Food Control Laboratory Directorate, Kayseri 
Food Control Laboratory Directorate, Kocaeli Food Control Laboratory Directorate, The Foundation for Children with Leukemia Laboratory, Mersin Food Control Laboratory Directorate, Mersin MRL Central Residue Research Laboratory, MSM Food control laboratory, Nanolab Food, Feed and water analysis laboratory, Ordu Food Control Laboratory Directorate, SGS Supervise Monitoring Studies Control Services, STA Quality control Food Laboratory, TekirdaĞ Food Control Laboratory Directorate for their participation to the validation tests. We thank Harun Kocaağa for his technical assistance.

\section{FINANCIAL \& COMPETING INTERESTS DISCLOSURE}

This work was supported by Turkish Scientfic and Research Council (TÜBITAK) project number 110G139 and 110G126. Authors of this paper do not have any conflict of interest. The authors have no other relevant affiliations or financial involvement with any organization or entity with a financial interest in or financial conflict with the subject matter or materials discussed in the manuscript apart from those disclosed.

No writing assistance was utilized in the production of this manuscript.

\section{OPEN ACCESS}

This work is licensed under the AttributionNonCommercial-NoDerivatives 4.0 Unported License. To view a copy of this license, visit http://creativecommons.org/licenses/ by-nc-nd/4.0/

\section{REFERENCES}

1. Bueno D, Istamboulie G, Muñoz R, Marty JL. Determination of mycotoxins in food: a review of bioanalytical to analytical methods. Appl. Spectrosc. Rev. 50(9), 728-774 (2015).

2. Li Y-F, Sun Y-M, Beier RC et al. Immunochemical tech niques for multianalyte analysis of chemical residues Chem. 88, 25-40 (2017)

3. Ertekin O, Guloglu FB, Pirincci S et al. Antibody based systems for the determination of mycotoxins in food and feed. Curr. Opin. Biotechnol. 24, S23 (2013).

4. Fan G-C, Zhu H, Du D, Zhang J-R, Zhu J-J, Lin Y. enhanced photoelectrochemical immunosensing platform based on CdSeTe@CdS:Mn core-shell quantum dots-sensitized $\mathrm{TiO}_{2}$ nanocrystals conjugated sign
antibodies. Anal. Chem. 88(6), 3392-3399 (2016).

5. Lin Y, Zhou Q, Tang D, Niessner R, Knopp D. Signal-on photoelectrochemical immunoassay for aflatoxin b1 based on enzymatic product-etching $\mathrm{MnO}_{2}$ nanosheets for dissociation of carbon dots. Anal. Chem. 89(10). 5637-5645 (2017).

6. Pirinçci ȘȘ, Ertekin Ö, Laguna DE, Özen FȘ, Öztürk ZZ, Öztürk S. Label-free QCM immunosensor for the detection of ochratoxin A. Sensors 18(4), 1161 (2018).

7. Evtugyn G, Subjakova V, Melikishvili S, Hianik T. Affinity biosensors for detection of mycotoxins in food. Adv. Food Nutr. Res. 85, 263-310 (2018).

8. Ertekin Ö, Öztürk S, Öztürk ZZ. Label free QCM immunobiosensor for AFB1 detection using monoclonal IgA antibody as recognition element. Sensors 16(8), 1274 (2016).

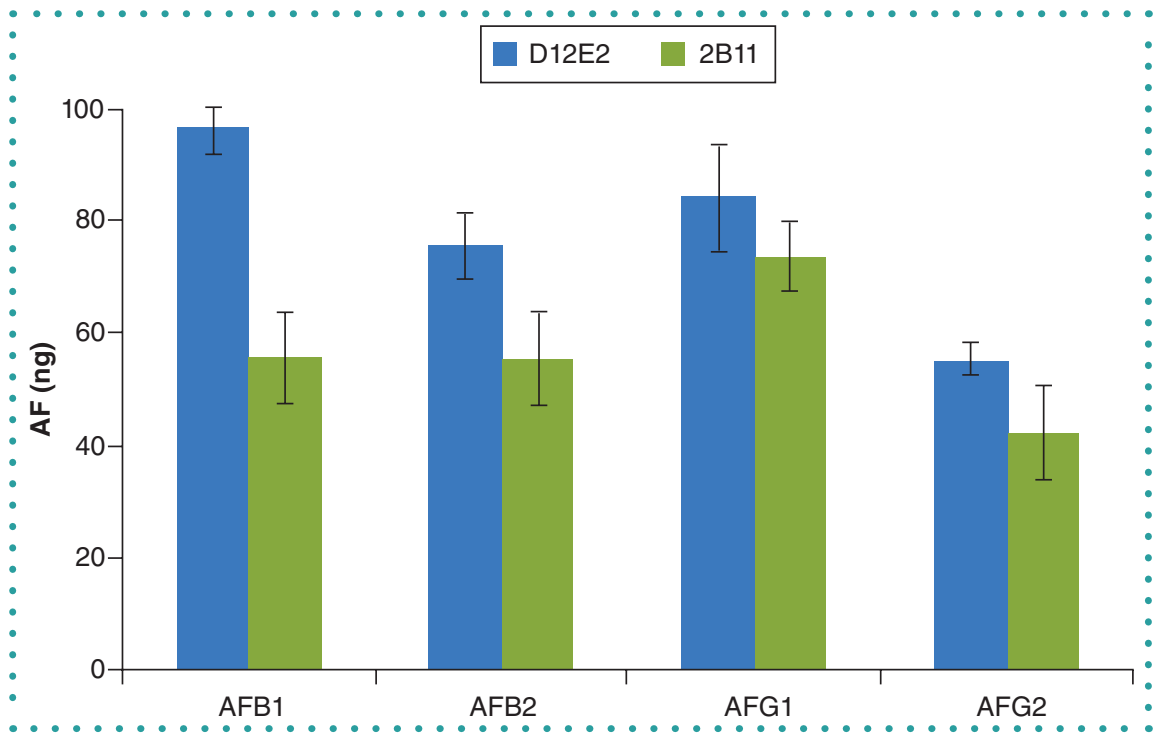

Figure 7. Immunoaffinity column overload test performances of D12E2 and 2B11. Error bars represent standard deviations of three independent replicas.

AF: Aflatoxin.

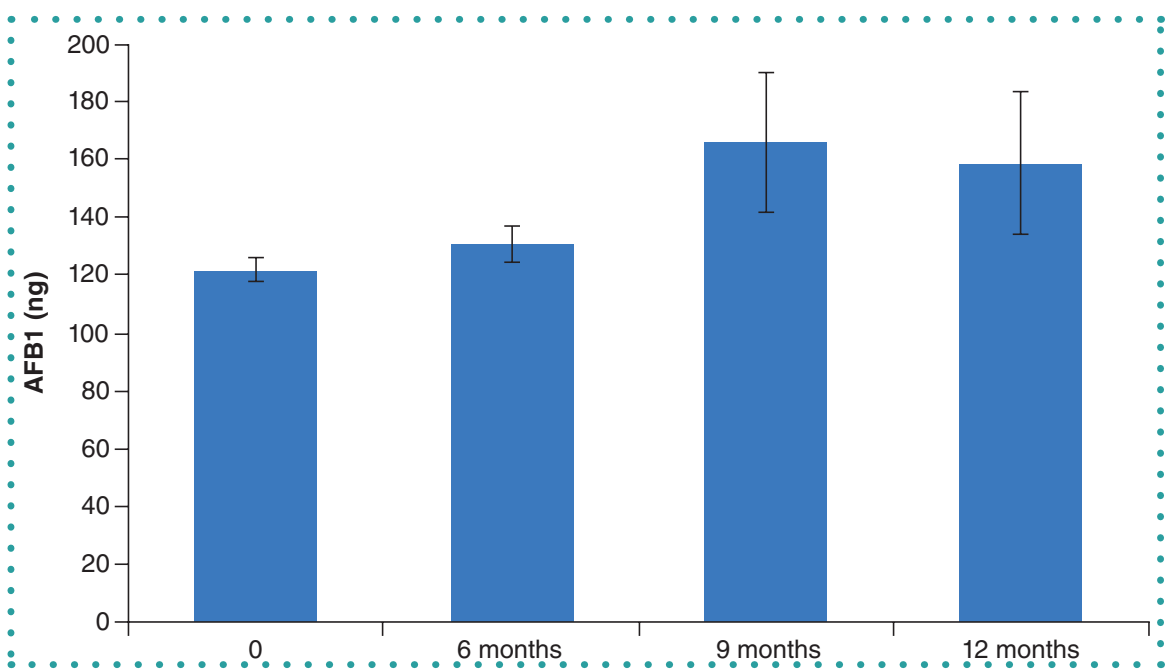

Figure 8. AFB1 binding capacity of immunoaffinity columns after 6,9 and 12 months storage at $+4^{\circ} \mathrm{C}$. Error bars represent standard deviations of three independent replicas.

9. Wang X, Niessner R, Tang D, Knopp D. Nanoparticle-based immunosensors and immunoassays fo aflatoxins. Anal. Chim. Acta 912, 10-23 (2016).

10. Wild D. (Ed.) The immunoassay handbook: theory and applications of ligand binding, ELISA and related techniques. Newnes, 2013.

11. Marx V. Finding the right antibody for the job. Nat. Methods. 10(8), 703-707 (2013).

12. Ertekin Ö, Pirinçci Ş, Öztürk S. Monoclonal lgA antibodies for aflatoxin immunoassays. Toxins 8(5), 148 (2016)

13. Ertekin Ö, Akçael E, Kocaağa H, Öztürk S. Biological activity of the carrier as a factor in immunogen design for haptens. Molecules 23(11), 2977 (2018).

14. Yakes BJ, Buijs J, Elliott CT, Campbell K. Surface plasmon resonance biosensing: Approaches for screening and characterising antibodies for food diagnostics. Talanta 156-157, 55-63 (2016).

15. Ertekin Ö, Akçael E, Polat $H$, Öztürk S. YF. Hybridoma Technology and Developing Antibody Based Diagnostic Systems. Tubitak-Mam, Kocaeli, 1-82 (2012).

16. Fitzgerald V, Leonard P. 9 Next-Generation Immunoassays. In: Immunoassays. CRC Press, CRC Press Taylor \& Francis Group, FL, USA, 255-289 (2017)

17. Marroquín-Cardona AG, Johnson NM, Phillips TD, Hayes AW. Mycotoxins in a changing global environment $-\mathrm{a}$ review. Food Chem. Toxicol. 69, 220-230 (2014).

18. FAO. Worldwide regulations for mycotoxins in food and feed in 2003. Public Health 1-14 (2004).

19. Alim M, Iqbal SZ, Selamat J, Ariño A. Regulations for food toxins. In: Food Safety. Springer International Publishing, 33-39 (2016)

20. Berthiller F, Brera C, Crews $C$ et al. Developments in mycotoxin analysis: an update for 2014-2015. World Mycotoxin J. 9(1), 5-30 (2016).

21. Shephard GS. Aflatoxin analysis at the beginning of the twenty-first century. Anal. Bioanal. Chem. 395(5), 1215-24 (2009)

22. Uchigashima M, Saigusa M, Yamashita $\mathrm{H}$ et al. Development of a novel immunoaffinity column for aflatoxin analysis using an organic solvent-tolerant monoclonal antibody. J. Agric. Food Chem. 57(19), 8728-8734 (2009).

23. Zhang X, Song M, Yu X et al. Development of a new broad-specific monoclonal antibody with uniform affinity for aflatoxins and magnetic beads-based enzymatic immunoassay. Food Control. 79, 309-316 (2017).

24. Pan D, Li G, Hu H et al. Direct Immunoassay for facile and sensitive detection of small molecule aflatoxin $B 1$ based on nanobody. Chem. A Eur. J. 24(39), 9869-9876 (2018). 
(A)

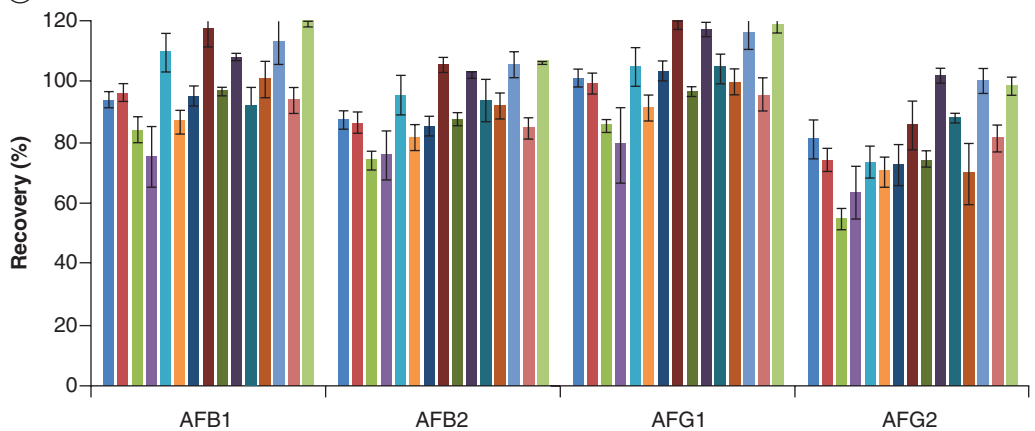

(B)

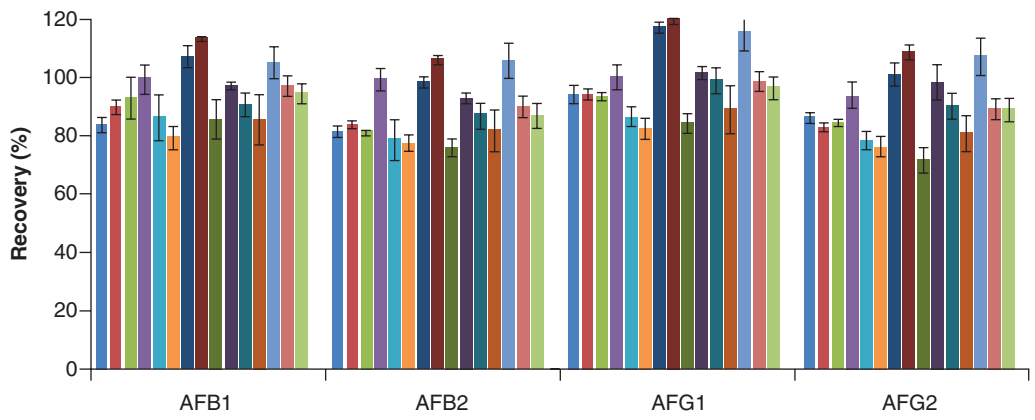

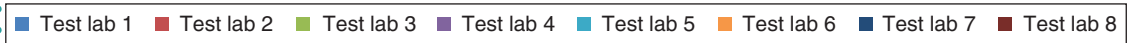

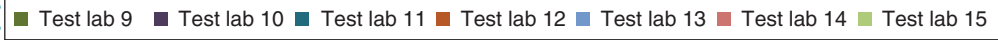

Figure 9. Validation of immunoaffinity columns in hazelnut (A) and wheat flour (B). $5 \mathrm{ng}$ of each aflatoxin derivative was loaded to the columns. Recovery rates represent the ratio of measured aflatoxins to loaded toxin. Error bars represent standard deviations of six replicas.

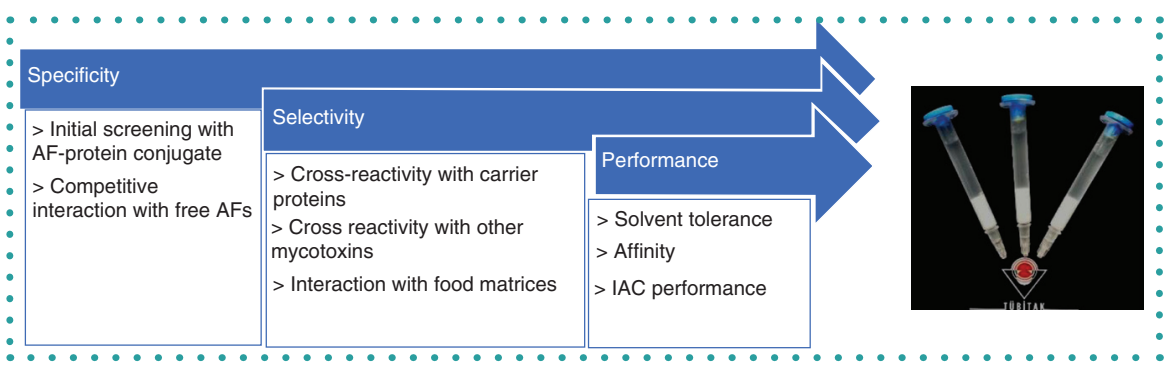

Figure 10. Selection scheme for aflatoxins-specific antibodies to be used for immunoaffinity column development.

AF: Aflatoxin; IAC: Immunoaffinity column.

25. Velugula-Yellela SR, Williams A, Trunfio $\mathrm{N}$ et al. Impact of media and antifoam selection on monoclonal antibody production and quality using a high throughput micro-bioreactor system. Biotechnol. Prog. 34(1) 262-270 (2018).

26. Gagnon $P$. Technology trends in antibody purification. J. Chromatogr. A. 1221, 57-70 (2012).

27. Hammerschmidt N, Tscheliessnig A, Sommer R, Helk $B$, Jungbauer A. Economics of recombinant antibody production processes at various scales: industry-stand ard compared to continuous precipitation. Biotechnol. J. 9(6), 766-775 (2014).

28. Ertekin Ö, Pirinçci SS, Öztürk S. Monoclonal antibodies MAM-D3E4, MAM-D3C6, MAM-D12E2, and MAM-D4D6 against aflatoxins. Monoclon. Antib. Immunodiagn. Immunother. 35(2), 117-118 (2016).

29. Ertekin Ö, Arslankaraoğlu Akçael E, Yücel F. Monoclonal antibodies MAM-2B11, MAM-6E10, and MAM-8G12 against aflatoxins. Monoclon. Antib. Immunodiagn. Immunother. 35(2), 119-120 (2016).

30. Yücel F, Ertekin Ö. Hybridoma technology. In: Current applications in Biotechnology. Dündar M, Bağış H (Eds). Kayseri, 189-210 (2017)
31. AOAC. Official Methods of Analysis of AOAC International. Assoc. Off. Anal. Chem. Int. 2 (2000)

32. Institute of Turkish Standards Technical Commitee. Foodstuffs - determination of aflatoxin $B 1$ and the sum of aflatoxin B1, B2, G1 and G2 in peanuts, pistachios, figs, and paprika powder - High performance liquid chromatographic method with postcolumn derivatization and immunoaffinity column clean-up. TS EN 14123 (2009).

33. Zhang $\mathrm{H}$, Wang $\mathrm{M}$, Wang $\mathrm{Y}$ et al. Preparation and application of an immunoaffinity column based on an antibody with strong affinity and packing material with good stability. Food Addit. Contam. Part A. Chem. Anal. Control. Expo. Risk Assess. 30(5), 853-60 (2013).

34. Arakawa T, Tsumoto K, Ejima D. Alternative downstream processes for production of antibodies and antibody fragments. Biochim. Biophys. Acta. 1844(11), 2032-2040 (2014).

\section{EXECUTIVE SUMMARY}

$\nabla$ Antibodies are the basic components of immunoassays that are used for detection and quantification of a wide range of analytes including mycotoxins, which are important part of food safety issues.

$\nabla$ The success of antibody-based methods inevitably depends on the quality of the antibody. Although there are some ground rules for antibody selection such as affinity and selectivity, analyte- and assay-specific criteria are the ones that determine the ultimate success of the immunoassays.

$\nabla$ In this study, we proposed an effective monoclonal antibody selection procedure for the development of immunoaffinity columns (IACs) for aflatoxin (AF), which is the most risky mycotoxin. The antibody selection scheme was designed as follows: - Determination of antibody specificity with AF derivatives and other mycotoxins. In the case of AF's, cross-reactivity between AF isotypes is considered an advantage since it provides broader spectrum. - Determination of solvent tolerance with the solvents used in AF extraction from food samples. - Matrix interference effect assessment characterizing the interaction of antibodies with food extracts and low concentrations of $A F$ in food extracts. - Functional integration to IAC where resin-binding efficacy and column performances were evaluated.

$\triangle A n I A C$, which is used for sample clean-up prior to AF analysis in food samples, was used as representative immunoassay application with the selected antibody.

\ Using these selection criteria, MAM-D12E2 monoclonal antibody was superior to eight competing monoclonal antibodies for IAC development.

\ Developed IACs, denoted as AFLA-MAM, were produced in pilot scale to conduct validation tests with 15 independent certified AF analysis laboratories.

$\triangle$ AFLA-MAM demonstrated more than $90 \%$ recovery of $5 \mathrm{ng} A F B 1,-B 2$ and $-\mathrm{G} 1$ and more than $80 \%$ recovery of $5 \mathrm{ng} A F G 1$ in wheat flour and hazelnut extracts with less than $6 \%$ inter-laboratory $\%$ repeatability relative standard deviation for all AF derivatives. 